\title{
Association between hyperuricemia and metabolic syndrome in patients suffering from bipolar disorder
}

Jingxu Chen ${ }^{1 \dagger}$, Hongmei Chen ${ }^{1 \dagger}$, Junhui Feng ${ }^{2}$, Ligang Zhang ${ }^{1}$, Juyan $\mathrm{Li}^{1}$, Ran $\mathrm{Li}^{1}$, Shaoli Wang ${ }^{1}$, lan Wilson ${ }^{3}$, Alison Jones ${ }^{3}$, Yunlong Tan ${ }^{1}$, Fude Yang ${ }^{1 *}$ and Xu-Feng Huang ${ }^{3^{*}}$ (D)

\begin{abstract}
Background: Clinical studies have shown that bipolar patients have increased serum uric acid levels. High serum uric acid levels could play a role contributing to high prevalence of metabolic syndrome. Metabolic syndrome is known to increase the risk of developing a number of life threatening diseases including coronary heart disease, hypertension, and type 2 diabetes. This study investigated the association between hyperuricemia and metabolic syndrome and its components in individuals suffering from bipolar disorders.
\end{abstract}

Methods: This study recruited 318 inpatients suffering from bipolar disorders from Beijing Hui-Long-Guan Hospital in China and 160 healthy subjects from the same region as the controls. We used National Cholesterol Education Program Adult Treatment Panel III Adapted criteria (NCEP ATP-III A) for the diagnosis of metabolic syndrome. Hyperuricemia was determined as serum uric acid level above $420 \mu \mathrm{mol} / \mathrm{L}$ in men and $360 \mu \mathrm{mol} / \mathrm{L}$ in women ( $\mathrm{N}$ Engl J Med 359(17):1811-1821, 2008).

Results: Among 318 bipolar patients, there was higher prevalence of metabolic syndrome (42.5\%) and hyperuricemia (27.7\%) than healthy controls (21.9 and 11.9\%). Bipolar patients with metabolic syndrome had increased prevalence of hyperuricemia $(\mathrm{OR}=3.0, \mathrm{C} 195$ [1.7-5.4]). Hypertriglyceridemia and larger waist circumference (WC) were associated with hyperunicemia (OR=1.8, Cl95 [1.1-3.1], $\mathrm{OR}=1.9, \mathrm{Cl} 95$ [1.1-3.4]). Hyperuricemia was associated with metabolic syndrome in bipolar patients $(p<0.001)$ and especially with hypertriglyceridemia $(\mathrm{OR}=1.9, \mathrm{Cl} 95[1.1-3.1]$ and increased $\mathrm{WC}(\mathrm{OR}=2.1$ [1.2-4.0]). Bipolar patients over 50 years of age and hyperuricemia were highly prone to develop metabolic syndrome (OR=14.0, Cl95 [5.0-39.0]).

Conclusions: Hyperuricemia was highly associated with development of metabolic disorder particularly for aged patients suffering from bipolar disorders. Early prevention of hyperuricemia and metabolic syndrome may lead better life for bipolar patients when they get older.

Keywords: Bipolar, Hyperuricemia, Metabolic syndrome, Ageing

\section{Background}

Bipolar disorder is a chronic mental illness, which is associated with a potentially devastating long-term impact on the patient's health, as well as their job, social relationships and families [1-3]. The World Health Organization reported that bipolar disorder was the

\footnotetext{
*Correspondence: yangfd200@126.com; xhuang@uow.edu.au

${ }^{\dagger}$ Jingxu Chen and Hongmei Chen contributed equally to this work.

${ }^{1}$ Beijing Hui-Long-Guan Hospital, Peking University, Beijing 100096, China

${ }^{3}$ Illawarra Health and Medical Research Institute and School of Medicine,

University of Wollongong, Wollongong, NSW 2522, Australia

Full list of author information is available at the end of the article
}

seventh among severe diseases in the year 2000 [4]. People suffering from bipolar disorders have high mortality, which could result in a 10-20 year shorter lifespan compared to the general population [5]. These patients have a high prevalence of cardiovascular disease to which $35-40 \%$ of deaths are attributable, which is associated with metabolic syndrome [6]. Increased ageing population leads to high burden of bipolar disorder patients [2]. Therefore, it is important to investigate possible contributing factors in order to prevent metabolic

(c) The Author(s). 2018 Open Access This article is distributed under the terms of the Creative Commons Attribution 4.0 International License (http://creativecommons.org/licenses/by/4.0/), which permits unrestricted use, distribution, and reproduction in any medium, provided you give appropriate credit to the original author(s) and the source, provide a link to the Creative Commons license, and indicate if changes were made. The Creative Commons Public Domain Dedication waiver (http://creativecommons.org/publicdomain/zero/1.0/) applies to the data made available in this article, unless otherwise stated. 
syndrome, reduce cardiovascular risk, and allocate health care resources to bipolar patients.

Metabolic syndrome is characterized by visceral obesity, altered lipid and glucose profiles and hypertension, all of which are known to increase the risk of developing cardiovascular diseases and type 2 diabetes [7]. Although the causal factors of developing metabolic syndrome in bipolar disorder patients are largely unknown, some contributing factors are proposed. For example, the risk factors may be due to the side effects of an unhealthy lifestyle including excessive food intake and reduced energy expenditure caused by mental illness or drug treatment, or inability to access appropriate health care [8-10].

Uric acid is the final oxidative product in the degradation of purine nucleotides. It has been evidenced by several studies that high serum uric acid levels were as a potential causal factor leading to high prevalence of metabolic syndrome and its components, including central obesity, hypertension, hyperlipidemia, diabetes, and insulin resistance [11-13]. Recently, clinical studies have confirmed that bipolar patients in all phases of the illness, especially manic episode, had increased serum uric acid levels [14-16]. Study also shows that the estimated effect between bipolar disorder and uric acid levels was partially mediated by metabolic abnormalities [17]. Therefore, the hyperuricemia and metabolic syndrome may reciprocally affect each other, which impairs glucose and lipid metabolism. This study investigated the relationship between hyperuricemia and metabolic syndrome and its components in individuals suffering from bipolar disorder.

\section{Methods}

\section{Subjects}

This study was carried out in Beijing Hui-Long-Guan hospital, a city-owned psychiatric hospital, China. A total of 318 patients $($ male/female $=150 / 168)$ were recruited from the inpatients suffering bipolar disorders. The study was conduction from July 2015 to June 2017. Patients were diagnosed as bipolar disorder based on DSM-IV diagnostic criteria for Bipolar Disorder I/II. Patients were referred by their psychiatrists to our research team. Patients were between 18 and 65 years of age and Han ethnic Chinese, agreed to participate in the study, and signed consent form either themselves or the first degree of their relative if the patient's condition did not allow him or her to do so. The research team evaluated the patients including their disease history, current symptoms, and general conditions. Those patients excluded were: 1) diagnosed with substance abuse within the previous 3 months, 2) pregnant or breast-feeding, and 3 ) those suffering from a neural degenerative disease including dementia and mental retardation.
One hundred and sixty healthy controls (male/female $=74 / 86)$ having no significant differences in age $( \pm 1$ year) and gender ratio to the patients were recruited from the same local community through the advertisement in media and pamphlets distributed to local residents (Table 1). We have performed psychiatric examination to all participants. Controls having a history of mental illness or substance abuse were excluded. The protocol of this study was approved by the Human Ethics Committee of Beijing Hui-Long-Guan Hospital and all patients were provided with a written informed consent in accordance with National Health and Medical Research Council Guidelines.

\section{Assessment}

The height and weight of all subjects were measured on the same calibrated weight scale standing barefoot with light clothes. Body mass index was calculated for all subjects. Patients with a BMI $\geq 25 \mathrm{~kg} / \mathrm{m}^{2}$ were considered overweight [18]. Waist circumference was measured at the mid-point level between the inferior costal margin and superior iliac crest at the time that the subject was at the end of his/her expiration while standing. A standard mercury manometer was used to measure blood pressure with the patient in a supine position. We recorded two readings with $5 \mathrm{~min}$ apart for blood pressure recordings. If one of the two blood pressure readings were greater than $130 / 85 \mathrm{mmHg}$, we took a third reading $30 \mathrm{~min}$ later. We then used the lowest of three readings in the analysis according to a previous study [19]. All subjects underwent venipuncture between 6:00 am and 7:00 am after overnight fasting $(\sim 12 \mathrm{~h})$, and the blood samples were analyzed on the same day. Serum concentrations of blood glucose, triglycerides, high-density lipoprotein cholesterol, and uric acid were measured using commercial kits (Beckman Coulter, Brea, California, USA) and an OLYMPUS AU 2700 automatic biochemical analyzer.

\section{The definition of metabolic syndrome and hyperuricemia} The present study used NCEP ATP-III-A for the diagnosis of metabolic syndrome [20]. This is because it has adjusted waist circumference for those of European descent to be more appropriate for Asian waist size [20] and sets a more stringent fasting glucose concentration to $5.6 \mathrm{mmol} / \mathrm{L}$ [21]. NCEP-ATP-III-A criteria requires the presence at least three of the following components: 1) increased waist circumference (WC): WC greater than $90 \mathrm{~cm}$ in men or $80 \mathrm{~cm}$ in women; 2) hypertriglyceridemia: triglycerides greater than $1.70 \mathrm{mmol} / \mathrm{L}(150$ $\mathrm{mg} / \mathrm{dL})$; 3) high density lipoprotein cholesterol (HDL-C): HDL-C lower than $1.03 \mathrm{mmol} / \mathrm{L}(40 \mathrm{mg} / \mathrm{dL})$ in men or $1.29 \mathrm{mmol} / \mathrm{L}(50 \mathrm{mg} / \mathrm{dL})$ in women; 4) hypertension: blood pressure greater than $130 \mathrm{mmHg}$ systolic or 
Table 1 Socio-demographic and clinical characteristics of bipolar patient and health control groups

\begin{tabular}{|c|c|c|c|c|}
\hline Variable & $\begin{array}{l}\text { Patient Group } \\
(n=318)\end{array}$ & $\begin{array}{l}\text { Control Group } \\
(n=160)\end{array}$ & $X^{2} / t$ & $p$ \\
\hline Age (years) & $39.2 \pm 13.1$ & $38.5 \pm 11.3$ & 0.532 & 0.595 \\
\hline Male, n (\%) & $150(47.2)$ & $74(46.3)$ & 0.006 & 0.807 \\
\hline Education (years) & $11.8 \pm 3.5$ & $11.7 \pm 3.9$ & 0.481 & 0.631 \\
\hline Married, n (\%) & $175(55.0)$ & $108(67.5)$ & 6.852 & 0.009 \\
\hline Smoker, n (\%) & $86(27.0)$ & $26(16.3)$ & 6.913 & 0.009 \\
\hline $\mathrm{BMI}\left(\mathrm{kg} / \mathrm{m}^{2}\right)$ & $24.8 \pm 3.3$ & $23.3 \pm 2.6$ & 4.955 & $<0.001$ \\
\hline Overweight, n (\%) & $145(45.6)$ & $48(30.0)$ & 10.757 & 0.001 \\
\hline Diastolic BP (mm Hg) & $75.2 \pm 8.4$ & $73.8 \pm 8.1$ & 1.793 & 0.074 \\
\hline Systolic BP (mm Hg) & $114.6 \pm 11.1$ & $113.5 \pm 11.1$ & 1.046 & 0.296 \\
\hline Hypertension, n (\%) & $91(28.6)$ & $29(18.1)$ & 6.231 & 0.013 \\
\hline WC (cm) & $87.5 \pm 11.1$ & $83.6 \pm 8.9$ & 3.844 & $<0.001$ \\
\hline Increased WC, n (\%) & $186(58.5)$ & $53(33.8)$ & 26.062 & $<0.001$ \\
\hline $\mathrm{HDL}-\mathrm{C}(\mathrm{mmol} / \mathrm{L})$ & $1.2 \pm 0.4$ & $1.3 \pm 0.4$ & 3.331 & 0.001 \\
\hline Low HDL-C, n (\%) & $151(47.5)$ & $50(31.3)$ & 11.512 & 0.001 \\
\hline Triglyceride (mmol/L) & $2.4 \pm 1.5$ & $1.4 \pm 1.1$ & 6.526 & $<0.001$ \\
\hline Hypertriglyceridemia, n (\%) & $118(37.1)$ & $37(23.1)$ & 9.497 & 0.002 \\
\hline FBG $(\mathrm{mmol} / \mathrm{L})$ & $5.0 \pm 1.2$ & $4.8 \pm 0.7$ & 2.660 & 0.008 \\
\hline Hyperglycaemia, n (\%) & $75(23.6)$ & $22(13.8)$ & 6.365 & 0.012 \\
\hline MetS, n (\%) & $135(42.5)$ & 35 (21.9) & 19.669 & $<0.001$ \\
\hline $\mathrm{UA}(\mathrm{mmol} / \mathrm{L})$ & $348.5 \pm 91.8$ & $300.2 \pm 76.6$ & 5.729 & $<0.001$ \\
\hline Hyperuricemia & $88(27.7)$ & 19 (11.9) & 15.290 & $<0.001$ \\
\hline
\end{tabular}

Data were mean \pm SD unless otherwise indicated. BMI: body mass index; BP blood pressure, $W C$ waist circumference, $H D L-C$ high density lipoprotein cholesterol, FBG fasting blood glucose, MetS metabolic syndrome, UA uric acid

greater than $85 \mathrm{mmHg}$ diastolic; and 5) hyperglycemia: fasting glucose concentration greater than $5.6 \mathrm{mmol} / \mathrm{L}$ $(100 \mathrm{mg} / \mathrm{dL})$, or diagnosed as type 2 diabetes. In addition, treatment with specific drugs was also considered including triglyceride, cholesterol, and glucose lowering drugs and blood pressure lowering drugs. Hyperuricemia was defined as serum level of uric acid $>$ $420 \mu \mathrm{mol} / \mathrm{L}(7.0 \mathrm{mg} / \mathrm{dL})$ for men and $>360 \mu \mathrm{mol} / \mathrm{L}(6.0$ $\mathrm{mg} / \mathrm{dL}$ ) for women $[22,23]$.

\section{Statistical analysis}

Statistical analysis was carried out using SPSS 15.0 for Windows (SPSS Inc., Chicago, USA). Demographics, clinical measures, and laboratory values were reported using measures of means and standard deviation. Group difference was compared using t-test for continuous variables having normal distribution and Mann-Whitney test for variables, which were not normal distribution including triglyceride, illness duration and $\mathrm{CPZ}$ equivalent dose. Chi-square test was used for categorical variable analyses. Univariate analysis was used to identify significant association between variables and metabolic syndrome. Simple binary logistic regression was used to establish correlation of metabolic syndrome and hyperuricemia as responding variable. Odds ratios and 95\% confidence intervals for all independent variables were determined. Sample size calculation was set at an alpha value of 0.05 , power $85 \%$ based on a previous study [24]. Marital status, illness duration, and illness episode were eliminated as confounding factors. All statistical tests were two-tailed, with alpha level set at 0.05 .

\section{Results}

Demographic and clinical characteristics of subjects

A total of 362 inpatients suffering from bipolar disorders were enrolled in this study. Forty-four patients (12.2\%) were excluded since there were no fasting blood and/or anthropometry data such as body weight, height, blood pressure, and waist circumference. Patients $(n=318)$ and control subjects $(n=160)$ had no significant differences in age and gender ratio $(p>0.05)$. Demographic and clinical characteristics of the study population were shown in Table 1.

The bipolar patient group had lower marriage rate $(p$ $=0.009)$ and higher proportion of smokers $(p<0.01)$ than the control group. Patients suffering from bipolar disorders were overweight $(p=0.001)$, high BMI $(p<$ $0.001)$, larger WC $(p=0.013)$, and low serum HDL-C 
$(p=0.001)$, increased triglyceride $(p<0.001)$, high fasting blood glucose $(p=0.002)$, and increased uric acid $(p<0.001)$ compared to control subjects without bipolar disorder. There were no statistical differences in systolic and diastolic blood pressures between patients and control subjects (both $p>0.05$ ).

\section{Bipolar patients had high prevalence of metabolic syndrome and hyperuricemia}

The prevalence of both hyperuricemia and metabolic syndrome was higher in bipolar patients compared to control subjects $(27.7 \%$ vs. $11.9 \%, p<0.001$ and $42.5 \%$ vs. $21.9 \%, p<0.001)$. Patients having metabolic syndrome had increased WC (58.5\%), hypertriglyceridemia (37.1\%), hyperglycemia (23.6\%), and hypertension (28.6\%) and decreased HDL-C (47.5\%) (Table 1). Bipolar patients had high prevalence of hyperuricemia than control subjects $(27.7 \%$ vs $11.9 \%, p<0.001)$.

\section{Factors associated with metabolic syndrome and hyperuricemia}

Hyperuricemia and metabolic syndrome in bipolar patients were associated with overweight, longer duration of the illness, and manic or mixed episodes (all $p<0.05$ ). Metabolic syndrome was associated with ageing and uses of mood stabilizer and antipsychotics (all $p<0.05$ ) (Table 2). Hyperuricemia was more common in male patients than female patients $(p<0.05)$. Bipolar patients with hyperuricemia had a high prevalence of metabolic syndrome than bipolar patients without hyperuricemia
(Table 3). Hyperuricemia was associated with hypertriglyceridemia and hyperglycemia, but not with hypertension, in bipolar patients.

\section{Association between metabolic syndrome and hyperuricemia}

The factors that correlated with the presence of metabolic syndrome were ages including 30 and 49 years $(\mathrm{OR}=2.2$, CI95[1.1-4.2], > 50 years $(\mathrm{OR}=8.6$, CI95[4.118.0], overweight $(\mathrm{OR}=3.0, \quad \mathrm{CI} 95[1.8-5.5])$, antipsychotic use $(\mathrm{OR}=3.6, \mathrm{CI} 95[1.7-7.5])$, mood stabilizer use $(\mathrm{OR}=2.4, \mathrm{CI} 95[1.1-5.3])$ and hyperuricemia $(\mathrm{OR}=$ 3.0, CI95[1.7-5.4]) (Table 4). The hyperuricemia were higher with increased WC $(\mathrm{OR}=2.1, \mathrm{CI} 95[1.2-4.0])$ and hypertriglyceridemia (OR = 1.9, CI95[1.1-3.1]) (Table 5). Bipolar patients having hyperuricemia and age greater than 50 years were more prone to develop metabolic syndrome $(\mathrm{OR}=14.0$, CI95[5.0-38.8]) (Fig. 1).

\section{Discussion}

The prevalence of metabolic syndrome in bipolar patients varies significantly from 8.5 to $67 \%$ from study to study reported in the literature [24-28]. A possible explanation for such large discrepancies may be due to different ethnicities, regions, dietary habits, and genetic backgrounds of patients investigated [29]. For example, high prevalence (67\%) was reported in an Australian study and $53 \%$ prevalence in an Indian study in bipolar patients suffering metabolic syndrome [25, 27]. Low prevalence of metabolic syndrome in bipolar patients

Table 2 Characteristics of bipolar patients with metabolic syndrome and hyperuricemia

\begin{tabular}{|c|c|c|c|c|c|c|}
\hline \multirow[t]{2}{*}{ Variable } & \multicolumn{3}{|c|}{ Metabolic syndrome } & \multicolumn{3}{|c|}{ Hyperuricemia } \\
\hline & Yes $(n=135)$ & No $(n=183)$ & $p$ & Yes $(n=86)$ & No $(n=232)$ & $p$ \\
\hline Age (years) & $44.1(12.5)$ & $35.4(12.6)$ & $<0.001$ & $40.5(13.4)$ & $38.6(13.0)$ & 0.265 \\
\hline Male, n (\%) & $67(49.6)$ & $83(45.4)$ & 0.450 & $50(56.8)$ & $100(43.5)$ & 0.033 \\
\hline Education (years) & $11.5(3.6)$ & $12.10(3.4)$ & 0.104 & $11.4(3.2)$ & $12.0(3.5)$ & 0.150 \\
\hline Smoker, n (\%) & $42(31.1)$ & $44(24.0)$ & 0.161 & $26(29.5)$ & $60(26.1)$ & 0.534 \\
\hline Married, n (\%) & $83(61.5)$ & $92(50.3)$ & 0.047 & $47(53.4)$ & $128(55.7)$ & 0.719 \\
\hline Illness duration (year) & $15.9(11.3)$ & $9.9(9.3)$ & $<0.001$ & 14.25 (10.6) & $11.9(10.6)$ & 0.013 \\
\hline Over weight, n (\%) & $85(63.0)$ & $60(32.8)$ & $<0.001$ & $52(59.1)$ & $93(40.4)$ & 0.003 \\
\hline Illness episode, n (\%) & & & 0.012 & & & 0.001 \\
\hline Manic/hypomanic & $91(67.4)$ & $104(56.8)$ & & $68(77.3)$ & $127(55.2)$ & \\
\hline Depressive & $31(23.0)$ & $69(37.7)$ & & $14(15.9)$ & $86(37.4)$ & \\
\hline Mixed & $5(3.7)$ & $1(0.5)$ & & $3(3.4)$ & $3(1.3)$ & \\
\hline Euthymic & $8(5.9)$ & $9(4.9)$ & & $3(3.4)$ & $14(6.1)$ & \\
\hline BPD type $\|, n(\%)$ & $9(6.7)$ & $12(6.6)$ & 0.969 & $6(6.8)$ & $15(6.5)$ & 0.924 \\
\hline Antipsychotics use, n (\%) & $120(88.9)$ & $135(73.8)$ & 0.001 & $72(81.8)$ & $183(79.6)$ & 0.652 \\
\hline CPZ equivalents (mg/d) & $344.7(205.9)$ & $297.7(248.1)$ & 0.030 & 3602 (209.8) & $307.0(236.1)$ & 0.081 \\
\hline Mood stabilizer use, n (\%) & $118(87.4)$ & $144(78.7)$ & 0.044 & $74(84.1)$ & $188(81.7)$ & 0.662 \\
\hline
\end{tabular}

Data were mean \pm SD unless otherwise indicated. $B P D$ bipolar disorder, $C P Z$ chlorpromazine 
Table 3 Association between hyperuricemia and metabolic syndrome and its components

\begin{tabular}{llllll}
\hline Variable & \multicolumn{3}{l}{ Hyperuricemia } & $X^{2}$ & $p$ \\
\cline { 2 - 3 } & Yes $(\mathrm{n}=86)$ & No( $\mathrm{n}=232)$ & & \\
\hline MetS, n (\%) & $55(62.5)$ & $80(34.8)$ & 20.015 & $<0.001$ \\
Increased WC, n (\%) & $63(71.6)$ & $123(53.5)$ & 8.600 & 0.003 \\
Low HDL-C, n (\%) & $47(53.4)$ & $104(45.2)$ & 1.713 & 0.191 \\
Hypertriglyceridemia, n (\%) & $44(50.0)$ & $74(32.2)$ & 8.666 & 0.003 \\
Hypertension, n (\%) & $30(34.1)$ & $61(26.5)$ & 1.785 & 0.182 \\
Hyperglycaemia, n (\%) & $29(33.0)$ & $46(20.0)$ & 5.927 & 0.015 \\
\hline
\end{tabular}

MetS metabolic syndrome, WC waist circumference, $H D L-C$ high density lipoprotein cholesterol

was reported in French (18.5\%) and Spanish (22.4\%) studies $[24,26]$. There are two other Indian studies reports that the prevalence of metabolic syndrome in bipolar patients is about $40 \%,[20,30]$, which is similar to $42 \%$ found in this study. On the other hand, the prevalence of metabolic syndrome in control subjects was $21.9 \%$ in the present study, which was similar to previous Chinese studies in normal population $(24.5 \%)$ [31].

Visceral obesity should be closely monitored as the prevalence of larger WC was significantly higher in bipolar patients than control subjects (58.5\% vs $33.8 \%)$. Visceral obesity is associated with metabolic syndrome, type 2 diabetes and coronary heart disease [32]. The prevalence of metabolic syndrome in bipolar patients was about eight times higher in the bipolar patients with age over 50 years than the bipolar patients with age less than 30 years. This could be due to increased uric acids, which worse insulin sensitivity in elderly patients. Patients having longer illness duration and experiencing manic or mixed episodes had higher rates of metabolic syndrome. The prevalence of gender difference having metabolic syndrome in bipolar patients is controversial. Some studies have reported that the prevalence of metabolic syndrome in male bipolar patients was about twice higher than female patients; but negative and opposite

Table 4 Associations between the various factors and the risk of having metabolic syndrome

\begin{tabular}{llll}
\hline Variable & OR & $95 \% \mathrm{Cl}$ & $p$ \\
\hline$<30$ years of age & 1.000 & Reference & - \\
$30-49$ years of age & 2.149 & $1.122-4.177$ & 0.021 \\
$\geq 50$ years of age & 8.587 & $4.087-18.044$ & $<0.001$ \\
$\mathrm{BMI} \geq 25 \mathrm{~kg} / \mathrm{m} 2$ & 3.005 & $1.767-5.110$ & $<0.001$ \\
Antipsychotics $^{\mathrm{a}}$ & 3.595 & $1.722-7.497$ & 0.001 \\
Mood stabilizer $^{\mathrm{b}}$ & 2.397 & $1.087-5.285$ & 0.030 \\
Hyperuricemia $^{c}$ & 3.029 & $1.685-5.443$ & $<0.001$
\end{tabular}

a: use of antipsychotic drug at clinical dose, ${ }^{b}$ : use of mood stabilizer at clinical dose, ${ }^{\text {c: }}$ serum uric acid $>420 \mu \mathrm{mol} / \mathrm{l}$ for men and $>360 \mu \mathrm{mol} / /$ for women [21]
Table 5 Associations between WC and hypertriglyceridemia with the risk of having hyperuricemia

\begin{tabular}{llll}
\hline Variable & OR & $95 \% \mathrm{Cl}$ & $p$ \\
\hline Increased WC & 2.128 & $1.233-4.034$ & 0.007 \\
Hypertriglyceridemia & 1.870 & $1.112-3.121$ & 0.017 \\
\hline WC waist circumference & & &
\end{tabular}

results were also reported in other studies [27, 33, 34]. The data presented in this study suggested no gender differences to develop metabolic syndrome in bipolar patients. About $80 \%$ of bipolar patients were prescribed atypical antipsychotic drugs and/or mood stabilizes, which were strongly linked to metabolic syndrome found in the current study.

Our results confirmed previous data that serum uric acid concentrations in bipolar patients were significantly higher than healthy controls $[15,17,35]$. Animal study shows that uric acid induces endothelial dysfunction and overproduction of reactive oxygen species, which has been considered as a major factor of insulin resistance [36]. In humans, hyperuricemia is also associated with insulin resistance and metabolic syndrome [37, 38]. It is possible that elevated uric acid worse insulin sensitivity and metabolic syndrome and vice versa. Both hyperuricemia and metabolic syndrome increase the risk of cardiovascular disease and dementia in elderly people [39]. Ageing is not necessarily associated increased blood uric acid [40]. This study showed that bipolar patient with hyperuricemia and over 50 years of age have very high prevalence for metabolic disorders and its components. Therefore, a special caution should be taken for preventing cardiovascular diseases when there is hyperuricemia in elderly bipolar patients.

Prevention and treatment of hyperuricemia are clearly important in terms of reducing the prevalence of metabolic syndrome in patients suffering from bipolar disorder. Since metabolic syndrome increases the risks of a number of life threatening diseases, reinstalling hyperuricemia back to normal level may help to reduce diabetes and kidney and cardiovascular diseases in these patients.

This study has some limitations. First, only inpatients with bipolar disorder were included, who tend to suffer more severely, have more comorbidities, and higher rates of pharmacological treatment than those of outpatients. Therefore, our data do not necessarily reflect the prevalence of metabolic syndrome of outpatients suffering from bipolar disorder. Second, antidepressant (eg: mirtazapine) uses were not obtained in this study, which could cause weight gain and metabolic disorders [41]. Finally, other possible confounding factors were not ruled out, which could play a role contributing to the development of metabolic syndrome including types and 


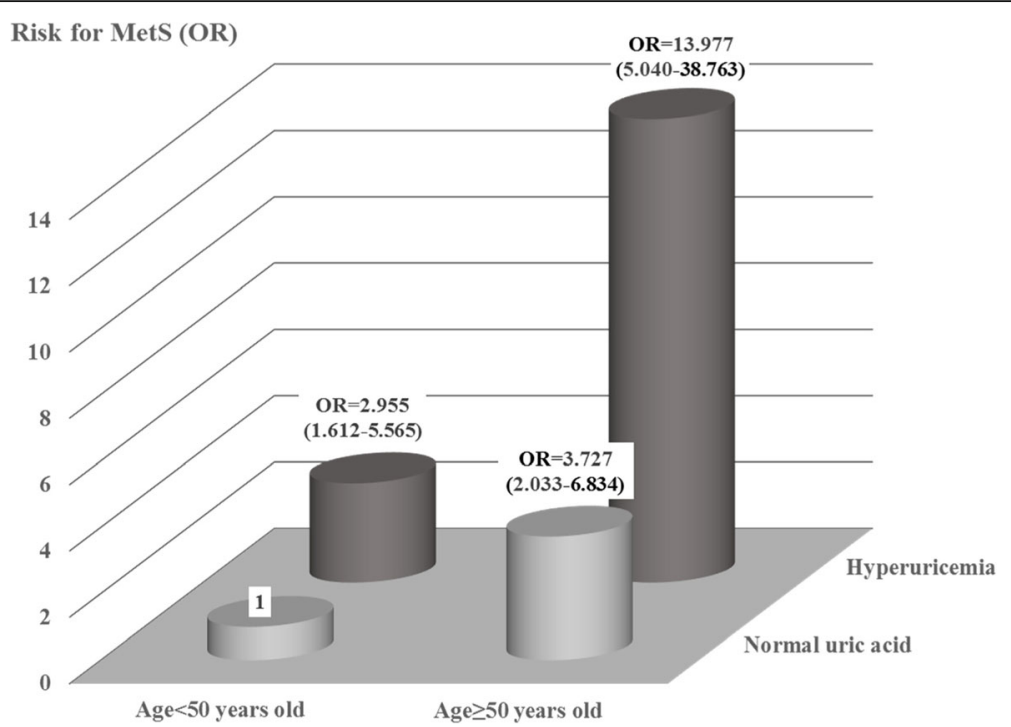

Fig. 1 Shows interaction between age $\geq 50$ years of age or $<50$ years of age and hyperuricemia for metabolic syndrome. Odd ratios are based on 95\% confidence interval

duration of antipsychotic drugs used, diet, physical activity, socioeconomic status, and alcohol use.

\section{Conclusions}

Hyperuricemia is more common in bipolar patients with metabolic syndrome. The high prevalence of metabolic syndrome and hyperuricemia may be due to hyperglycemia, ageing, antipsychotic and mood stabilizer uses, illness duration, and visceral obesity. It is possible that elevated uric acid disrupts metabolic regulation and on the other hand, metabolic disorders could further worse hyperuricemia in bipolar patients. Bipolar patients with hyperuricemia and age greater than 50 years were highly prone to develop metabolic syndrome.

\section{Abbreviations}

BMI: body mass index; BP: blood pressure; BPD: bipolar disorder; $\mathrm{Cl}$ : confidence interval; CPZ: chlorpromazine; DSM-IV: Diagnostic and Statistical Manual of Mental Disorders, 4th Edition; FBG: fasting blood glucose; HDL-C: high density lipoprotein cholesterol; MetS: metabolic syndrome; NCEP ATP-III A: National Cholesterol Education Program Adult Treatment Panel III Adapted criteria; OR: odds ratio; SPSS: Statistical Package for the Social Sciences; UA: uric acid; WC: waist circumference

\section{Acknowledgements}

The authors would like to thank Ning Wang, Yanxia Kang, Xia Du, Xuanwang, and Feng Yan for all of their hard work and contributions to this study.

\section{Funding}

This study was supported by the National Key Technologies R\&D Program of China (2015BAl13B01)and the Special Foundation of Beijing Municipal Science \& Technology Commission, China (grant no: Z131107002213099).

\section{Availability of data and materials}

The datasets used and/or analyzed during the current study are available from the first author on reasonable request.

\section{Authors' contributions}

Conception of the study: XF Huang, JX Chen, FD Yang. JX Chen was the project manager. HM Chen, JH Feng, LG Zhang, JY Li, R Li, and SL Wang were responsible for recruiting the patients, performing the clinical rating, collecting all samples and helping with statistical analysis and manuscript preparation. XF Huang, JX Chen, FD Yang, YL Tan, A Jones and I Wilson were involved in interpreting the data and writing and editing the paper. All authors have read and approved the manuscript.

\section{Ethics approval and consent to participate}

This research was approved by the Human Ethics Committee of Beijing HuiLong-Guan Hospital. All patients were provided with written informed consent. Participation was voluntary and participants could withdraw at any time from the study.

\section{Consent for publication}

Not applicable.

\section{Competing interests}

The authors have no conflicts of interest to disclose.

\section{Publisher's Note}

Springer Nature remains neutral with regard to jurisdictional claims in published maps and institutional affiliations.

\section{Author details}

'Beijing Hui-Long-Guan Hospital, Peking University, Beijing 100096, China. ${ }^{2}$ Jining Psychiatric Hospital, Jining 272051, China. ${ }^{3}$ lllawarra Health and Medical Research Institute and School of Medicine, University of Wollongong, Wollongong, NSW 2522, Australia.

Received: 2 July 2018 Accepted: 14 November 2018

Published online: 18 December 2018

\section{References}

1. Revicki DA, Matza LS, Flood E, Lloyd A. Bipolar disorder and health-related quality of life : review of burden of disease and clinical trials. Pharmacoeconomics. 2005:23(6):583-94.

2. Ferrari AJ, Stockings E, Khoo JP, Erskine HE, Degenhardt L, Vos T, Whiteford HA. The prevalence and burden of bipolar disorder: findings from the global burden of disease study 2013. Bipolar Disord. 2016;18(5):440-50.

3. Vigo D, Thornicroft G, Atun R. Estimating the true global burden of mental illness. Lancet Psychiatry. 2016;3(2):171-8. 
4. Morselli PL, Elgie R, Cesana BM. GAMIAN-Europe/BEAM survey II: cross-national analysis of unemployment, family history, treatment satisfaction and impact of the bipolar disorder on life style. Bipolar Disord. 2004;6(6):487-97.

5. Miller C, Bauer MS. Excess mortality in bipolar disorders. Curr Psychiatry Rep. 2014;16(11):499.

6. Weiner M, Warren L, Fiedorowicz JG. Cardiovascular morbidity and mortality in bipolar disorder. Ann Clin Psychiatry. 2011;23(1):40-7.

7. de Almeida KM, Moreira CL, Lafer B. Metabolic syndrome and bipolar disorder: what should psychiatrists know? CNS Neurosci Ther. 2012;18(2):160-6.

8. Mitchell AJ, Malone D, Doebbeling CC. Quality of medical care for people with and without comorbid mental illness and substance misuse: systematic review of comparative studies. Br J Psychiatry. 2009;194(6):491-9.

9. De Hert M, Cohen D, Bobes J, Cetkovich-Bakmas M, Leucht S, Ndetei DM, Newcomer JW, Uwakwe R, Asai I, Moller HJ, et al. Physical illness in patients with severe mental disorders. II. Barriers to care, monitoring and treatment guidelines, plus recommendations at the system and individual level. World Psychiatry. 2011;10(2):138-51.

10. Kilbourne AM, Rofey DL, McCarthy JF, Post EP, Welsh D, Blow FC. Nutrition and exercise behavior among patients with bipolar disorder. Bipolar Disord. 2007:9(5):443-52.

11. Meshkani R, Zargari M, Larijani B. The relationship between uric acid and metabolic syndrome in normal glucose tolerance and normal fasting glucose subjects. Acta Diabetol. 2011;48(1):79-88.

12. Robles-Cervantes JA, Ramos-Zavala MG, Gonzalez-Ortiz M, Martinez-Abundis E, Valencia-Sandoval C, Torres-Chavez A, Espinel-Bermudez C, SantiagoHernandez NJ, Hernandez-Gonzalez SO. Relationship between serum concentration of uric acid and insulin secretion among adults with type 2 diabetes mellitus. Int J Endocrinol. 2011;2011:107904

13. Kanbay M, Jensen $T$, Solak Y, Le M, Roncal-Jimenez C, Rivard C, Lanaspa MA, Nakagawa T, Johnson RJ. Uric acid in metabolic syndrome: from an innocent bystander to a central player. Eur J Intern Med. 2016;29:3-8.

14. Albert U, De Cori D, Aguglia A, Barbaro F, Bogetto F, Maina G. Increased uric acid levels in bipolar disorder subjects during different phases of illness. J Affect Disord. 2015;173:170-5.

15. Kesebir S, Suner O, Yaylaci ET, Bayrak A, Turan C. Increased uric acid levels in bipolar disorder: is it trait or state? J Biol Regul Homeost Agents. 2013;27(4):981-8.

16. Bartoli F, Crocamo C, Mazza MG, Clerici M, Carra G. Uric acid levels in subjects with bipolar disorder: a comparative meta-analysis. J Psychiatr Res. 2016:81:133-9.

17. Bartoli F, Crocamo C, Gennaro GM, Castagna G, Trotta G, Clerici M, Carra G. Exploring the association between bipolar disorder and uric acid: a mediation analysis. J Psychosom Res. 2016;84:56-9.

18. WHO-Expert-Consultation. Appropriate body-mass index for Asian populations and its implications for policy and intervention strategies. Lancet. 2004;363(9403):157-63.

19. Grover S, Aggarwal M, Chakrabarti S, Dutt A, Avasthi A, Kulhara P, Malhotra N, Somaiya M, Chauhan N. Prevalence of metabolic syndrome in bipolar disorder: an exploratory study from North India. Prog NeuroPsychopharmacol Biol Psychiatry. 2012;36(1):141-6.

20. Tan CE, Ma S, Wai D, Chew SK, Tai ES. Can we apply the National Cholesterol Education Program Adult Treatment Panel definition of the metabolic syndrome to Asians? Diabetes Care. 2004:27(5):1182-6.

21. Grundy SM, Cleeman JI, Daniels SR, Donato KA, Eckel RH, Franklin BA, Gordon DJ, Krauss RM, Savage PJ, Smith SC Jr, et al. Diagnosis and management of the metabolic syndrome: an American Heart Association/ National Heart, Lung, and Blood Institute scientific statement. Circulation. 2005;112(17):2735-52.

22. Feig DI, Kang DH, Johnson RJ. Uric acid and cardiovascular risk. N Engl J Med. 2008;359(17):1811-21.

23. Yu FN, Shi YX, Cheng HY, Huang XL, Liu SS. An observational study on the relationship between serum uric acid and hypertension in a northern Chinese population aged 45 to 59 years. Medicine (Baltimore). 2017:96(17):e6773.

24. Godin O, Etain B, Henry C, Bougerol T, Courtet P, Mayliss L, Passerieux C, Azorin JM, Kahn JP, Gard S, et al. Metabolic syndrome in a French cohort of patients with bipolar disorder: results from the FACE-BD cohort. J Clin Psychiatry. 2014;75(10):1078-85 quiz 1085.

25. John AP, Koloth R, Dragovic M, Lim SC. Prevalence of metabolic syndrome among Australians with severe mental illness. Med J Aust. 2009;190(4):176-9.
26. Garcia-Portilla MP, Saiz PA, Benabarre A, Sierra P, Perez J, Rodriguez A, Livianos $L$, Torres $P$, Bobes $J$. The prevalence of metabolic syndrome in patients with bipolar disorder. J Affect Disord. 2008;106(1-2):197-201.

27. Kumar A, Narayanaswamy JC, Venkatasubramanian G, Raguram R, Grover S, Aswath M. Prevalence of metabolic syndrome and its clinical correlates among patients with bipolar disorder. Asian J Psychiatr. 2017;26:109-14.

28. Silarova B, Giltay EJ, Van Reedt Dortland A, Van Rossum EF, Hoencamp E, Penninx BW, Spijker AT. Metabolic syndrome in patients with bipolar disorder: comparison with major depressive disorder and non-psychiatric controls. J Psychosom Res. 2015;78(4):391-8.

29. Grover S, Malhotra N, Chakrabarti S, Kulhara P. Metabolic syndrome in bipolar disorders. Indian J Psychol Med. 2012;34(2):110-8

30. Malhotra N, Kulhara P, Chakrabarti S, Grover S. A prospective, longitudinal study of metabolic syndrome in patients with bipolar disorder and schizophrenia. J Affect Disord. 2013;150(2):653-8.

31. Li R, Li W, Lun Z, Zhang H, Sun Z, Kanu JS, Qiu S, Cheng Y, Liu Y. Prevalence of metabolic syndrome in mainland China: a meta-analysis of published studies. BMC Public Health. 2016;16:296.

32. Kato MM, Currier MB, Gomez CM, Hall L, Gonzalez-Blanco M. Prevalence of metabolic syndrome in Hispanic and non-Hispanic patients with schizophrenia. Prim Care Companion J Clin Psychiatry. 2004;6(2):74-7.

33. Czepielewski L, Daruy Filho L, Brietzke E, Grassi-Oliveira R. Bipolar disorder and metabolic syndrome: a systematic review. Rev Bras Psiquiatr. 2013;35(1):88-93.

34. Nayerifard R, Bureng MA, Zahiroddin A, Namjoo M, Rajezi S. Comparison of metabolic syndrome prevalence in patients with schizophrenia and bipolar I disorder. Diabetes Metab Syndr. 2017;11(Suppl 1):S411-6.

35. Muti M, Del Grande C, Musetti L, Marazziti D, Turri M, Cirronis M, Pergentini I, Corsi M, Dell'Osso L, Corsini GU. Serum uric acid levels and different phases of illness in bipolar I patients treated with lithium. Psychiatry Res. 2015;225(3):604-8.

36. Soltani Z, Rasheed K, Kapusta DR, Reisin E. Potential role of uric acid in metabolic syndrome, hypertension, kidney injury, and cardiovascular diseases: is it time for reappraisal? Curr Hypertens Rep. 2013:15(3):175-81.

37. Li C, Hsieh MC, Chang SJ. Metabolic syndrome, diabetes, and hyperuricemia. Curr Opin Rheumatol. 2013:25(2):210-6.

38. Osgood K, Krakoff J, Thearle M. Serum uric acid predicts both current and future components of the metabolic syndrome. Metab Syndr Relat Disord. 2013;11(3):157-62

39. Latourte A, Soumare A, Bardin T, Perez-Ruiz F, Debette S, Richette P. Uric acid and incident dementia over 12 years of follow-up: a population-based cohort study. Ann Rheum Dis. 2018;77(3):328-35.

40. Gephardt MC, Hanlon TJ, Matson CF. Blood uric acid values as related to sex and age. JAMA. 1964;189:1028-9.

41. Carvalho AF, Sharma MS, Brunoni AR, Vieta E, Fava GA. The safety, tolerability and risks associated with the use of newer generation antidepressant drugs: a critical review of the literature. Psychother Psychosom. 2016;85(5):270-88.

Ready to submit your research? Choose BMC and benefit from:

- fast, convenient online submission

- thorough peer review by experienced researchers in your field

- rapid publication on acceptance

- support for research data, including large and complex data types

- gold Open Access which fosters wider collaboration and increased citations

- maximum visibility for your research: over $100 \mathrm{M}$ website views per year

At $\mathrm{BMC}$, research is always in progress.

Learn more biomedcentral.com/submission 